\title{
Infection and antimicrobial prescribing control in the new millennium: nightmare or nirvana?
}

\author{
Barry Cookson
}

Antimicrobial resistance is a good example of interactive evolution between man's therapeutic, infection control, and health care delivery practices and the microbes. Are we facing a nightmare or nirvana? Our nightmare is perhaps that there may soon be no effective treatment for infections caused by antimicrobial resistant organisms, and that these would occur at such frequencies that we would in essence have returned to the preantimicrobial era. ${ }^{12}$ We have in some parts of the world almost run out of antimicrobials for certain bacterial infections ${ }^{3}$ (I shall ignore in this article the challenges of viral, fungal, and protozoal infections), and physicians are having to face another nightmare scenario: harming patients with toxic antimicrobials that would not otherwise be marketed, or performing surgery without effective antimicrobial cover to prevent them dying from infection.

The title suggests that nirvana might be considered the opposite - a heavenly state where organisms are again susceptible. However, it is actually defined as "a state of blessedness when the soul is united with divine infinity and all personality is extinguished." This definition could also imply a certain complacency and I shall return to this possibility shortly.

There was a great temptation when invited to write this article to let my imagination run wild. What will the future bring? Predictions are of obvious interest to patients, healthcare workers, politicians, and those investing in the stock market. Will we have optimised our genetic and environmental stress factors, ${ }^{4}$ or robotised ourselves using nanotechnology ${ }^{5}$ for maximum longevity? Will we have increased our resistance to infection with new vaccine strategies ${ }^{67}$ or other approaches? ${ }^{8}$ Will we be using (reusable) gene chip technology, ${ }^{9}$ bacterial sniffing, ${ }^{10}$ or other technology ${ }^{11}$ for immediate "Starship Enterprise" remote disease diagnosis? Might nanostructured artificial inorganic/organic biomaterials ${ }^{12}$ or cloned tissue replacement techniques ${ }^{13}$ have resolved any residual problems? Surgery and, no doubt, novel therapeutic approaches will have been transformed by nanorobotics ${ }^{14}$ and yet to be described new technologies. Such predictions are fraught with difficulties, as several well known science fiction authors in this century have found. Will, for instance, nanotechnology ${ }^{15}$ realise its full potential or become a disaster as countries' economies are ruined by computer viruses using evolutionary algorithms? Will we solve the major global problems of rampant AIDS, starvation, drought, non-existent sanitation, and failure of current birth control programmes? All these will have immense knock on effects on health- care. I have, instead, chosen to try and outline what we will need to address in terms of hospital infection and antimicrobial prescribing practices in the first few decades of the next century.

There can be no doubt that hospital patient "soils" will change dramatically. Current and new diagnostic and surgical techniques will further reduce the need for patient admissions. Nosocomial rather than hospital infection control will be an increasing requirement as more patients are treated in nursing homes, general practices, and day care centres. All of these will have to ensure optimal infection control standards as they introduce more and more "bedside" diagnostic, ${ }^{16}$ surgical, or other interventions. The few patients requiring hospital admission will be more sick, and prevention of hospital infection will become an even greater challenge to healthcare workers.

\section{Microbial strategies}

The microbes are at least as ingenious as our good selves. They have amassed among their number an armoury of mechanisms to avoid the action of almost every antimicrobial agent. They often "improvise," calling upon existing mechanisms within their own or other microbial species, or even develop new ones by mutation. ${ }^{3}{ }^{17}$ Microbes exist in their countless billions and are capable of multiplying at rates several orders of magnitude greater than our own; their potential to explore mutational events when stressed is awesome. Resistance is often described before antimicrobials are used clinically and occurs even where these agents are totally, or partly, synthesised. Their reservoir of resistance genes extends across veterinary and human ecological niches. Our microbial adversaries adopt a variety of such strategies in a way that has similarities to guerrilla warfare. Early on it was thought, or perhaps hoped, that antimicrobial resistance would compromise microbial pathogenicity. However, this generalisation appears to be untrue $^{18}$ and microbes, resistant or otherwise, are unlikely to evolve to become less virulent. Enterococci, for example, once considered the innocuous cockroach of bacteria, are capable of causing infections, especially in immunosuppressed patients, ${ }^{2}$ and are able to transfer their resistances to "genuine" pathogens such as $S$ aureus in vitro and in vivo. ${ }^{19}$

\section{Mankind's strategies}

Microbes will continue to practice interactive evolution. The introduction of robotics and automation, together with new biological assay technologies (for example, homogeneous time resolved fluorescence and combinatorial liquid 
phase synthesis of peptide and non-peptide libraries and deriving libraries from these libraries) will enable the rapid screening of enormous numbers of compounds. ${ }^{20-22} \mathrm{Com}-$ puterised modelling will further improve the design and prediction of the toxicity and pharmacokinetics of new agents. We will continue to explore prebiotics and probiotics, ${ }^{23}$ traditional, ${ }^{24}$ or herbal ${ }^{25}$ remedies. Some of the new antimicrobial design strategies including those against resistance and virulence mechanisms ${ }^{26}$ and using phages ${ }^{27}$ will provide interesting challenges to the microbial pathogens. They hopefully will be effective in the immunocompromised (that is, they will be bactericidal rather than bacteriostatic) and also will not disturb the commensal flora (many of which also have these resistance mechanisms), so causing Clostridium difficile associated diarrhoea, ${ }^{28}$ superinfection, or other problems.

However, it is unlikely that Ehrlich's magic bullet (the microbe's nightmare) will be realised in the next century, neither is it likely to be our favoured strategy unless, as alluded to above, such treatment can be prevented from affecting our own commensal flora. Perhaps our being in a Nirvana-like state contributed to our delusions in this century that we had won the battle against the microbes? We ignored the evidence that resistance would become a significant problem and prescribed antimicrobials in a haphazard, or at best a poorly coordinated manner ${ }^{12-31}$ and have made them available over the counter with inadequate regulations. ${ }^{32}$ We have abused the amazing therapeutic arsenal made available to the health care community and underestimated opponents with far more tricks up their sleeves (or rather inside or on their surfaces).

It has at last dawned on "us" that the academic and pharmaceutical communities do not have many new classes of antimicrobials that will be available in the near future and that if and when they do arrive, there is the real threat we will again misuse them as we did their predecessors. However, microbes do have an Achilles heal: by and large they are pragmatic and a little lazy, merely responding as necessary to the prevailing environmental pressures. Our two major weapons in the control of antimicrobial resistance are antimicrobial prescribing control $^{33}{ }^{34}$ to reduce the advantages to organisms of becoming resistant, and effective infection control (especially handwashing) practices, to stop these organisms spreading. ${ }^{135-37}$ We will need to monitor the effectiveness of these solutions, as the evidence base for these is less than optimal. ${ }^{33} 3839$

\section{EU activities}

There have been several high profile initiatives to raise the profile of antimicrobial resistance and the importance of its prevention. One of the most impressive of these was the Microbial Threat Conference held in Denmark in 1998 (www.microbial.threat.dk) and its recommendations are listed in table 1 . It was agreed at this meeting that the implications of antimicrobial resistance in terms of morbidity, mortality, and costs were of urgent and global
Table 1 Summarised recommendations of the Microbial Threat meeting

- The EU and members states must recognise that antimicrobial resistance is a major European and global problem

- Pharmaceutical companies should be encouraged to develop new antimicrobial agents but these will not solve the problem in the near future

- The EU and member states should set up a European surveillance system of antimicrobial resistance

- The EU and member states need to collect data on the supply and consumption of antimicrobial agents

- The EU and member states should encourage the adoption of a wide range of measures to promote prudent use of antimicrobial agents

- The EU and member states and national research councils should make coordinated research on antimicrobial resistance a high priority

- A way should be found to review progress with these recommendations and proposals

importance and required an international effort to control. The transmission of resistant organisms through the food chain was another important consideration.

THE NEED FOR SURVEILLANCE OF RESISTANT ORGANISMS

Surveillance based upon clinically and epidemiologically relevant data was required to develop locally relevant therapeutic guidelines. Interaction between community and hospital and veterinary resistance data and prescribing information was required. It was agreed that a network of networks was the way forward, an approach already being used by the WHO. ${ }^{40}$ The surveillance systems had to provide timely, accessible, and agreed information which would identify effects of changes in prescribing or infection control and any other risk factors for resistance. Improvement in susceptibility testing and definitions of resistance were required.

THE NEED TO COLLECT DATA ON THE SUPPLY AND CONSUMPTION OF ANTIMICROBIAL AGENTS National data on the supply of antimicrobial agents for humans, horticulture, and aquaculture reveal interesting changes with time and differences between countries, and could be used to stimulate investigations and actions. There was much discussion on the different uses (therapeutic, prophylactic, and ergotropic) in animals. An EU strategy was required to develop a multinational database which would include data from all these sources. Political and financial support was required to assist those conducting research on patient prescribing practices and should also be considered in initiatives that are exploring standards of clinical practice.

ENCOURAGING GOOD PRACTICE ON THE USE OF ANTIMICROBIAL AGENTS

Steps were required to increase and improve patient diagnostic testing where infection was suspected. Guidelines for appropriate use of antimicrobials were required in all aspects of the therapeutic, prophylactic, and ergotropic use of these agents. These should indicate what should be done, not just what should not be done. The following counsel of perfection was outlined: 
"Treatment should be limited to bacterial infections using antibiotics directed against the causative agent, given in optimal dosage, dosage intervals, and length of treatment with steps taken to ensure maximum patient concordance with the treatment regimen, and only when the benefit of the treatment outweighs the individual and global risks."

There was considerable debate on the use of ergotropic agents and the majority (of this largely clinical microbiological audience) felt that these should be replaced with safer non-antimicrobial alternatives including better farming practices. A full risk assessment was required before taking any further decisions. The improved use of antimicrobial agents required education of all the key players: the veterinary and health care workers and the general public. Teams of hospital workers (pharmacists, clinical microbiologist/infectious disease physicians) were needed in every hospital. They could also cover other community institutions (for example, nursing and residential homes) and therapeutic monitoring activities at the primary/secondary care interface. Clinicians should be given the opportunity to approve the remit and recommendations of these teams. However, it was proposed that, where treatment did not comply with local guidelines, these teams could alter it, taking into account the needs of the patient.

There are several EU funded projects that are pursuing many of these goals. One project (Hospitals in Europe link for infection control through surveillance, HELICS II) has established an inventory of infection control and antimicrobial resistance control activities in the EU. In this project we have endeavoured to seek a consensus on what should be done in the EU over the next several years. A preliminary report is available over the internet (www.univ.lyon1.fr/iusi.nice). Outlined here are the main recommendations and their implications for the new millennium. It is anticipated that a fuller consensus of these issues will be sought in 2000. How they will then be progressed will depend on the EU countries' support.

\section{Recommendation 1: Surveillance methods, information, and data exchange need to be standardised}

We recommended that a European hospital infection control advisory board, including experts in nosocomial infection control policies and the major ongoing national/regional networks and related activities, will support the elaboration of a coordinated approach to surveillance. Various tools, including the organisation of workshops, would elaborate, validate, and disseminate standards for nosocomial infection surveillance methods (a continuation of the HELICS I effort). Collaborative clinical and health services research projects using data collected within the network of networks would be designed. Clearly the more comparable the surveillance standards and data quality evaluation systems, the easier it will be to establish such projects. We hope that we will learn much about the different approaches to health care delivery during this process of harmonisation. ${ }^{41}$ Other important initiatives could focus on infections occurring after hospital discharge and on the surveillance of ambulatory care, including its integration with other quality of care indicators. We have also suggested the consideration of an alert mechanism within a communication internet network, particularly for emerging infectious agents, new at risk situations, risk factors, technology linked hazards, and multiple antimicrobial resistant organisms. The United Kingdom has always been strong in this area, although ever shortening lengths of hospital stay will make it essential for post-discharge surveillance supported by laboratory investigation.

\section{Recommendation 2: European cooperation should foster the development of infection control standards, guidelines, and policies}

A European expert working party with representatives from each country would agree a strategy to support the development of infection prevention and control standards and guidelines and so avoid duplication of effort by establishing and revising a systematic literature review process and methods of evidence categorisation. These would be performed in agreed centre(s) (or might, of course, be rotated, as has been practised in Australia). The working party would prioritise and review regularly the guideline topics and serve as an appropriate forum to review the discrepancies in guideline statements and so identify areas where further research evidence is required. The processes whereby these standards and guidelines are made into effective local infection control policies would be explored and best practices shared between member states. These activities should interact with surveillance and audit cycles to accelerate the process in improving infection control practices and so reduce the burden of nosocomial infections. To assist in this process, an inventory of national guidelines should be made available and updated through the internet NICE (Nosocomial infection control in Europe) site to ensure the cross fertilisation of ideas and access to references and unpublished reports.

Recommendation 3: A European training programme in infection control and hospital epidemiology with educational fellowships should be set up

A common core standard curriculum for infection control training in Europe should be developed by a working party drawn from those playing a leading role in infection control training in each member state. This would ensure that a detailed inventory of short and long term courses throughout the EU is drawn up and made available through the NICE internet site, a crossroads for accessing useful educational material and advertising infection control training courses. A European training programme in infection control should be set up with a series of modules so designed to cover all the aspects of the previously established common curriculum. This effort should bring 
together infection control organisations, universities, and international scientific and professional societies. Fellowships should be made available in the EU according to national educational needs. Consideration should be given to the formation of a European Society/ Forum concerning the control of nosocomial infections which could be linked with the International Federation of Infection Control and other existing European societies.

\section{Recommendation 4: In view of the increasing importance of nosocomial infection control and antimicrobial resistance, there should be a greater investment in related research and development activities}

There should be allocation of more substantial resources to research in the infection control field in Europe. A working group should be convened to consider the various research priorities and criteria for project applications. Ways should also be explored in which the findings and activities of the current research groups in the EU might best be used. The Commission must ensure the greater coordination and synergy, rather than duplication, of current and future research efforts in this rapidly evolving field. The introduction of the thematic network concept in the fifth framework raises exciting possibilities for nosocomial infection and antimicrobial resistance control. The working group could advise the Commission on the priorities and criteria. Tenders should be proposed for multicentre European studies on topics described above (for example, surveillance methods, uses of surveillance data, quality indicators). The national departments of health and other grant providing bodies should be encourage to support the national components of EU funded projects where these require significant additional resources.

\section{Recommendation 5: Surveillance of antimicrobial resistance and antimicrobial use should take advantage of the extensive experience of nosocomial infection surveillance}

European nosocomial infection surveillance networks should be encouraged to include data on multiple resistance in organisms causing nosocomial infection as well as on antimicrobial use. A working party should be established to incorporate surveillance of antimicrobial resistance and antimicrobial consumption data into nosocomial infection surveillance networks, benefiting from the long standing experience of monitoring nosocomial infections. Learning from the experience of the HELICS I project, this working party should establish European common formats for input data and data reporting.

\section{Conclusions}

At last the international community is treating the challenges to infection control and antimicrobial prescribing practices more seriously. The actions outlined above are mindful of the essential role and involvement of the local infection control team and healthcare workers ("thinking globally and acting locally"). They will need to play a key role in the above actions, providing input, for instance, into the guideline process, and will need the resources to assist in local control policy design and the monitoring of their effectiveness through surveillance and audit review cycles. ${ }^{42}{ }^{43}$ Patients are becoming more involved in decision making regarding their treatment. ${ }^{44}$ New technologies will involve them and their relatives directly as current hospital treatment and diagnostic procedures move more and more into the community. It is essential that we encourage a healthy debate with patients, ${ }^{45}$ their relatives, and advocates as to what needs to be done to prevent our nightmare becoming our childrens' and grandchildrens' reality and realise nirvana.

I would like to thank Professor Jacques Fabrey, the leader, and all the other members of the steering group and project team of the HELICS II project.

1 Abou YZ, Acar JF, Ayliffe GAG, et al. Report of the World Health Scientific Working Group on monitoring and mangement of bacterial resistance to antimicrobial agents. Geneva: WHO, 1995 (WHO $\backslash C D S \backslash B V I \backslash 95.7)$.

2 Cookson BD. Glycopeptide-resistant enterococci-the threat examined. Culture 1998;19:1-5.

3 Levy SB. Antimicrobial resistance: bacteria on the defence $B M F ; 1998 ; 317: 612-13$.

4 Finch CE, Tanzi RE. Genetics of ageing. Science 1997;278: 407-11.

5 Minsky M. Will robots inherit the earth? Sci Am 1994;271: $108-13$

6 Ellis RW, Douglas RG. New vaccine technologies. $7 A M A$ 1994;271:929-31

7 Morris W, Steinhoff MC, Russell PK. Potential of polymer microencapsulation technology for vaccine innovation. Vaccine 1994;12:5-11.

8 Kerr JR. Cell adhesion in the pathogenesis of host defence against microbial infection. Mol Pathol 1999;52:220-30.

Cargill JF. Lebl M. New methods in combinatorial chemistry-robotics and parallel synthesis. Curr Opin Chem Biol 1997;1:67-71.

10 Greenwood JE, Crawley BA, Clark SI, et al. Monitoring wound healing by odour. $\mathcal{F}$ Wound Care 1997;6:219-21.

11 Padeken D, Sotiriou D, Boddy K, et al. Health care in remote areas. F Med Systems 1995;19:69-76.

12 Hubbell JA. Biomaterials in tissue engineering. BioTechnology 1995:13:565-76.

13 Winston R. The future of genetic manipulation. London: Phoenix, 1997.

14 Buckingham RA, Buckingham RO. Robots in operating theatres. BMF 1995;311:1479-82.

15 Drexler KE. Molecular nanomachines: physical principles and implementation strategies. Annu Rev Biophysics Biomol Structure 1994;23:377-405.

16 Borriello SP. Near patient microbiological tests. BMF 1999; 319:298-301.

17 Cookson BD. Staphylococcus aureus. In: Emmerson M, Kibbler C, Hawkey P, eds. Principles in clinical bacteriology. Oxford: John Wiley, 1997:109-30.

18 Lenski RE. The cost of antibiotic resistance-from the perspective of the bacterium. In: Antibiotic resistance: origins, evolution, selection, and spread. Chichester: John Wiley (Ciba Foundation Symposium 207), 1997:131-51.

19 Noble WC, Virani Z, Cree RGA. Co-transfer of vancomycin and other resistance genes from Enterococcus faecalis NCTC 12201 to Staphylococcus aureus. FEMS Microbiol Lett 1992;93:195-8.

20 Fauchere JL, Henlin JM, Boutin JA. Peptide and nonpeptide lead discovery using robotically synthesized soluble libraries. Can F Physiol Pharmacol 1997;75:683-9.

21 Blondells SE, Pérez-Payá E, Houghton RA. Synthetic combinatorial libraries: novel discovery strategy for identification of antimicrobial agents. Antimicrob Agents Chemother tion of antimicro

22 Houston JG, Banks M. The chemical-biological interface: developments in automated and miniaturised screening technology. Curr Opin Biotechnol 1997;8:734-40.

23 Fuller R, Gibson GR. Probiotics and prebiotics: microflora management for improved gut health. Clin Microbiol Infect 1998;4:477-80.

24 Tang J, Zhan S, Ernst E. Review of randomised controlled trials of traditional Chinese medicine. BMF 1999;319:160-

25 Carson CF, Cookson BD, Farrelly HD, et al. Susceptibility of methicillin-resistant Staphylococcus aureus to the essential oil of Melaleuca alternifolia. I Antimicrob Chemother 1995;35:421-4.

26 Chopra I, Hodgson J, Metcalf B, et al. The search for antimicrobial agents effective against bacteria resistant to mulmicrobial agents effective against bacteria resistant to mul-
tiple antibiotics. Antimicrob Agents Chemother 1997;41:497tiple 
27 Soothill JS. Treatment of experimental infections in mice with bacteriophage. F Med Microbiol 1992;37:247-9.

28 Cooke EM, Borriello SP, Brazier JS, et al, for DoH PHIS Working Group. The prevention and management of Clostridium difficile infection. Heywood: BAPS Health Publication Unit, 1994

29 McGavock $\mathrm{H}$, Webb $\mathrm{CH}$, Johnston GD, et al. Market penetration of new drugs in one United Kingdom region: implications for general practitioners and administrators. BMF 1993;307:1118-20.

30 Davey PG, Bax RP, Newey J, et al. Growth in the use of antibiotics in the community in England and Scotland in 1980-93. BMF 1996;312:613.

31 Gonzales R, Sande M. What will it take to stop physicians from prescribing antibiotics in acute bronchitis? Lancet 1995;345:665-6.

32 Reeves DS, Finch RG, Bax RP, et al. Self-medication of antibacterials without prescription (also called "over-the" use). A report of a Working Party of the British Society for Antimicrobial Chemotherapy. $\mathcal{f}$ Antimicrob Chemother 1999;44:163-77.

33 Huovinen P, Cars O. Control of antimicrobial resistance: time for action. BMF 1998;317:613-14.

34 Morse D. Directly observed therapy for tuberculosis, $B M \mathcal{F}$ Morse D. Directly

35 Glynn A, Ward V, Wilson J, et al. Hospital-acquired infection: surveillance, policies and practice. London: PHLS, 1997 (ISBN 0901144401 ).

36 Teare EL, Cookson B, French G, et al. Handwashing-a modest measure with big effects. BMF 1999;318:686.
37 Cookson BD, Emmerson AM, Sedgwick JE, et al. Standards in infection control in hospitals. Report of a combined working party of the Association of Medical Microbiology, Hospital Infection Society, Infection Control Nurses Association and the Public Health Laboratory Service. London: HMSO, 1993 (ISBN 090114436 3).

38 Turnidge J. What can be done about resistance? BMf 1998; 317:645-7.

39 McGowan JE. Do intensive hospital antibiotic control programs prevent the spread of antibiotic resistance? Infect Control Hosp Epidemiol 1994;15:478-83.

40 Williams RJ, Ryan MJ. Surveillance of antimicrobial resistance-an international perspective. BMF 1998;317: 651

41 Mertens R, Van den Berg JM, Veerman-Brenzikofer MLV, et al. International comparison of results of infection surveillance: The Netherlands versus Belgium. Infect Control Hosp Epidemiol 1994;15:574-80.

42 Thomson R, Lavender M, Madhok R. How to ensure guidelines are effective. BMF 1995;311:237-42.

43 Ward V, Wilson J, Taylor L, et al. Preventing hospital-acquired infection - clinical guidelines. London: PHLS, 1997 (ISBN 0 $90114441 \mathrm{X}$ )

44 OHPAT Workshop. Outpatient and home parenteral antibiotic therapy (OHPAT) in the UK: a consensus statement by a working party. Clin Microbiol Infect 1998;4:53751

45 Gould I, Shepherd D, Wilson G. Over the counter availability of antibiotics. F Antimicrob Chemother 1996;37:635-6. 